\title{
STRESS TRANSFER FROM AXIALLY LOADED FIBER TO MATRIX IN A MICROCOMPOSITE
}

CHUN-HWAY HSUEH

Metals and Ceramics Division, Oak Ridge National Laboratory, Oak Ridge, TN 37831

\begin{abstract}
The shear lag model has been used extensively to analyze the stress transfer in a singe fiberreinforced composite (i.e., a microcomposite). To achieve analytical solutions, various simplifications have been adopted in the stress analysis. Questions regarding the adequacy of those simplifications are discussed in the present study for the following two cases: bonded interfaces and frictional interfaces. Specifically, simplifications regarding (1) the radial dependences of axial stresses in the fiber and the matrix, and (2) Poisson's effect are addressed. For bonded interfaces, the latter can be ignored, and the former can generally be ignored. However, when the volume fraction of the fiber is high, the radial dependence of the axial stress in the fiber should be considered. For frictional interfaces, the former can be ignored, but the latter should be considered; however, it can be considered in an average sense to simplify the analysis. Comparisons among results obtained from analyses with various simplifications are made.
\end{abstract}

\section{INTRODUCTION}

Studies of fiber-reinforced ceramic composites have revealed that a substantial improvement in toughness is achieved via bridging of crack surfaces by strong intact fibers in a zone behind the crack tip [1-2]. The load in the crack region is sustained by the fibers, and catastrophic failure of the composite is avoided. To model the toughening effect, knowledge of the stress transfer from the fiber to the surrounding matrix in the bridging zone is required. To analyze this stress transfer, a representative volume element consisting of a fiber and a coaxial cylindrical shell of matrix (i.e., a microcomposite) is always considered, and the shear lag model [3-12] has been used extensively. However, due to the complexity of the stress transfer phenomena, analytical solutions are unattainable without simplifications in the stress analysis. Two questions regarding these simplifications are raised in the following.

When the fiber is subjected to loading in its axial direction, a nonuniform radial stress is induced along the fiber/matrix interface due to Poisson's effect. The stress analysis is formidable in the presence of Poisson's effect. The question is raised as to whether or not Poisson's effect can be ignored in the shear lag model. If Poisson's effect cannot be ignored, can it be treated in a simple way?

In the microcomposite, stresses are expected to vary in both the axial and the radial directions due to the stress transfer. However, whereas variations of axial stresses in the axial direction have been emphasized, variations of axial stresses in the radial direction have always been ignored. A second question is hence raised. Can the radial dependences of axial stresses be ignored in the analysis? If they can be ignored, what are the limitations?

The purpose of the present study is to address the above two questions. It should be noted that the interface can remain bonded or become debonded (and frictional) during the stress transfer process. Depending upon the characteristics of the interface (i.e., bonded or frictional), the stress transfer is governed by different constitutive equations. Hence, simplifications pertinent to stress transfer analyses for bonded and frictional interfaces are expected to be different. These differences will be discussed. Comparisons among results obtained from analyses with various simplifications will also be made.

THE SHEAR LAG MODEL

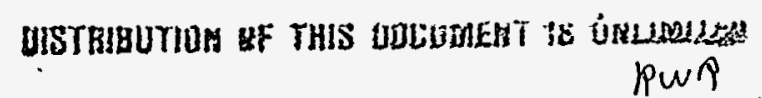

The submitted manuscript has been The submitted manuscript has b.S. authored by a contrector of tho. DEGovernment under contract No. U.S. ACO5-84OA2 1400. Accordingly. noxchuive. Government reteins a nonexchaive. roysity-tree icense to publish of roproduco the publushed form of this contriburion, or allow others to do so, for U.S. Government purposes."

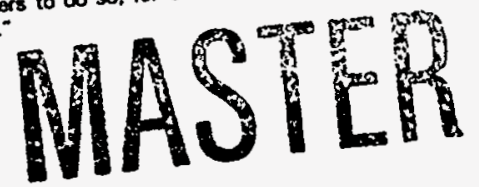




\section{DISCLAIMER}

\section{Portions of this document may be illegible in electronic image products. Images are produced from the best available original document.}


The shear lag model (Fig. 1) was proposed by Cox [3] to analyze the stress transfer problem in a microcomposite. In this model, a fiber with a radius, $a$, is embedded in a coaxial cylindrical shell of a matrix with a radius, $b$, such that $a^{2} / b^{2}$ corresponds to the volume fraction of fibers in the composite. As shown in Fig. 1, $t$ is the thickness of the composite (i.e., the embedded fiber length), $z$ is the direction parallel to the fiber axis, and an axial stress, $\sigma_{0}$, is applied on one end of the fiber (i.e., at $z=t$ in Fig. 1). The stress transfers from the fiber to the matrix through the interfacial shear stress, $\tau_{1}$. The fiber has a free surface at the other end (i.e., at $z=0$ ).

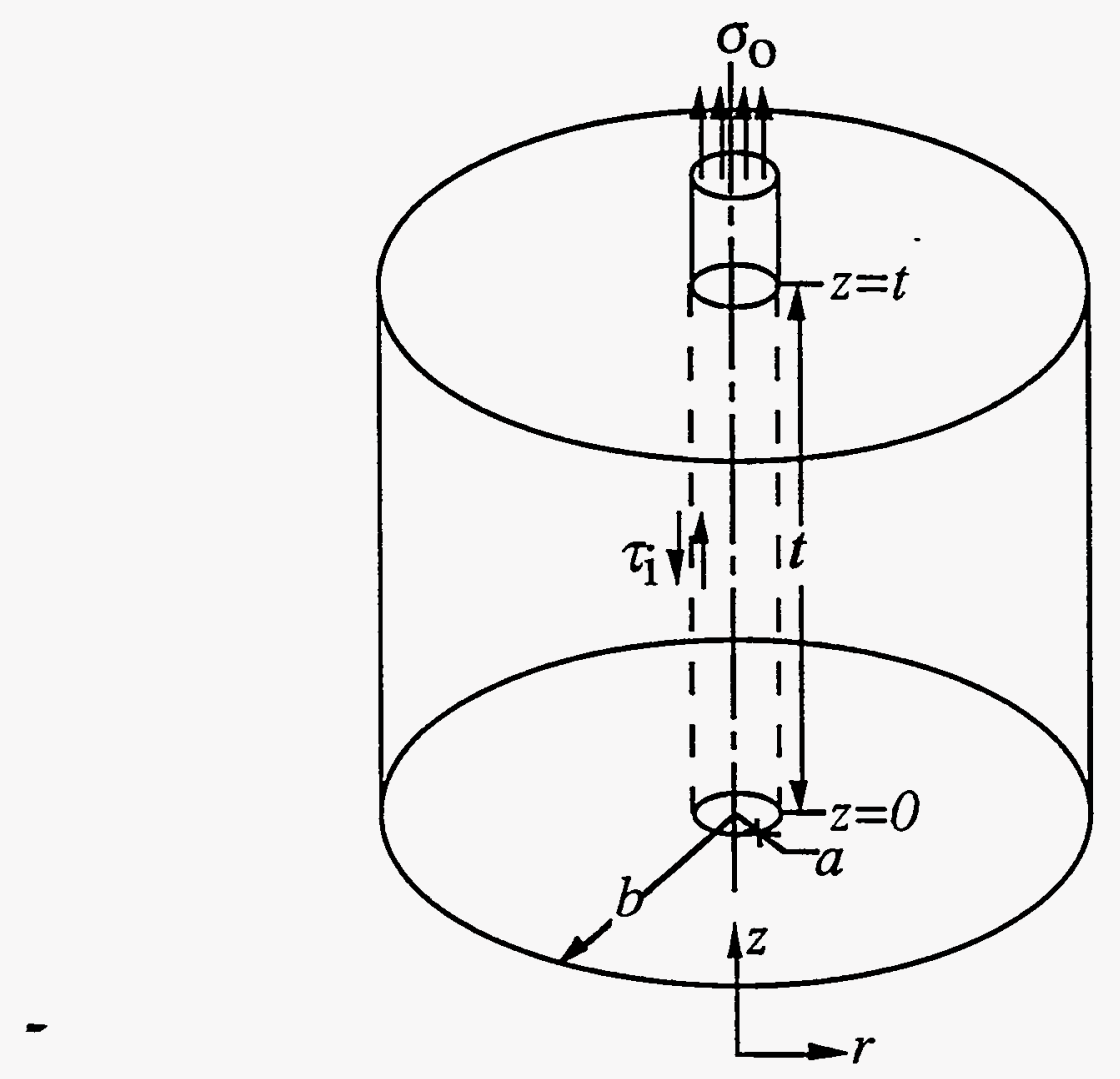

Fig. 1. Schematic showing the shear lag model used in analyzing the stress transfer from the axially loaded fiber to the matrix.

Adopting the shear lag model, analytical solutions of the stress transfer problem have been obtained by using various simplifications. These simplifications can be classified into two categories, i.e., simplifications regarding (1) the radial dependences of axial stresses in the fiber and the matrix, and (2) Poisson's effect of the fiber. In the classical shear lag model [3], both the radial dependences and Poisson's effect are ignored. The adequacy of the above simplifications is addressed, respectively, for bonded interfaces and frictional interfaces in the following.

\section{BONDED INTERFACES}

For bonded interfaces, continuities of the radial and the axial displacements are required. Whereas the interfacial radial stress is induced mainly by continuity of the radial displacement (i.e., Poisson's effect), the interfacial shear stress is induced mainly by continuity of the axial displacement. The interfacial radial stress induced by Poisson's effect has a negligible effect on the interfacial shear stress and, hence, on the stress transfer [13]. Compared to the solutions ignoring Poisson's effect, the solutions considering Poisson's effect can be obtained by replacing Young's modulus of the fiber, $E_{\mathrm{f}}$, by $E_{\mathrm{f}}$ such that [13] 


$$
E_{\mathrm{f}}{ }^{\prime}=\left[\frac{D-2\left(\frac{v_{\mathrm{f}} E_{\mathrm{m}}}{E_{\mathrm{f}}}+\frac{a^{2} v_{\mathrm{m}}}{b^{2}-a^{2}}\right) v_{\mathrm{m}}}{D-2\left(\frac{v_{\mathrm{f}} E_{\mathrm{m}}}{E_{\mathrm{f}}}+\frac{a^{2} v_{\mathrm{m}}}{b^{2}-a^{2}}\right) v_{\mathrm{f}}}\right] E_{\mathrm{f}}
$$

where $E$ and $v$ are Young's modulus and Poisson's ratio, and the subscripts $\mathrm{f}$ and $\mathrm{m}$ denote the fiber and the matrix, respectively, and $D$ is given by

$$
D=\frac{b^{2}+a^{2}}{b^{2}-a^{2}}+v_{\mathrm{m}}+\frac{\left(1-v_{\mathrm{f}}\right) E_{\mathrm{m}}}{E_{\mathrm{f}}}
$$

This replacement results in only slight differences. Specifically, $E_{\mathrm{f}}=E_{\mathrm{f}}$ when $v_{\mathrm{f}}=v_{\mathrm{m}}$.

Based on the shear lag model, the maximum interfacial shear stress occurs at the loaded surface which, in turn, has been used to define the strength-based debonding criterion. Strictly speaking, the maximum interfacial shear stress should occur at a very short distance underneath the loaded surface; however, this short distance is out of the scope of the shear lag model [14,15]. This maximum interfacial shear stress is a function of the embedded fiber length, $t$, however, it reaches its asymptote, $\tau_{0}$, at relatively short embedded fiber lengths $[4,5,8,16-18]$. To illustrate the adequacy of simplifications regarding radial dependences of axial stresses in the shear lag model, $\tau_{0}$ obtained from analyses with various simplifications is examined. Specifically, comparisons are made among predictions of $\tau_{0}$ obtained by (1) ignoring radial dependences in both the fiber and the matrix, $\sigma_{\mathrm{f}}$ and $\sigma_{\mathrm{m}},(2)$ considering the radial dependence of $\sigma_{\mathrm{f}}$ only, (3) considering the radial dependence of $\sigma_{\mathrm{m}}$ only, and (4) considering radial dependences of both $\sigma_{\mathrm{f}}$ and $\sigma_{\mathrm{m}}$.

Ignoring the radial dependences of both of and $\sigma_{\mathrm{m}}$, the result is $[4,5]$

$$
\tau_{\circ}=\frac{\sigma_{\mathrm{o}}}{2}\left[\frac{E_{\mathrm{m}}}{\left(1+v_{\mathrm{m}}\right) E_{\mathrm{f}} \ln (b / a)}\right]^{1 / 2}
$$

Considering only the radial dependence of of, the result is $[16,17]$

$$
\tau_{\circ}=\sigma_{\circ}\left\{\frac{E_{\mathrm{m}}}{\left(1+v_{\mathrm{f}}\right)\left[\frac{a^{2} E_{\mathrm{f}}}{b^{2}-a^{2}}+E_{\mathrm{m}}\right]}\right\}^{1 / 2}
$$

Considering only the radial dependence of $\sigma_{\mathrm{m}}$, the result is $[8,18]$

$$
\tau_{\mathrm{o}}=\frac{\sigma_{\mathrm{o}} E_{\mathrm{m}}}{2\left\{\left(1+v_{\mathrm{m}}\right) E_{\mathrm{f}}\left[\frac{a^{2} E_{\mathrm{f}}}{b^{2}-a^{2}}+E_{\mathrm{m}}\right]\left[\frac{b^{2}}{b^{2}-a^{2}} \ln \left(\frac{b}{a}\right)-\frac{1}{2}\right]\right\}^{1 / 2}}
$$




$$
\begin{gathered}
\tau_{\circ}=\frac{\sigma_{\mathrm{o}} A_{\mathrm{m}}}{2\left\{[ \frac { a ^ { 2 } E _ { \mathrm { f } } } { b ^ { 2 } - a ^ { 2 } } + P _ { 1 } E _ { \mathrm { m } } - P _ { 3 } E _ { \mathrm { f } } ] \left[\frac{b^{2}\left(1+v_{\mathrm{m}}\right) E_{\mathrm{f}}}{b^{2}-a^{2}}\left(\frac{b^{2}}{b^{2}-a^{2}} \ln \left(\frac{b}{a}\right)-\frac{3 b^{2}-a^{2}}{4 b^{2}}\right)\right.\right.} \\
\left.\left.+\frac{\left(1+v_{\mathrm{f}}\right) P_{1} E_{\mathrm{m}}}{4}+\frac{P_{2} E_{\mathrm{f}}}{2}\right]\right\}^{1 / 2}
\end{gathered}
$$

where $P_{1}, P_{2}$ and $P_{3}$ are given by

$$
\begin{gathered}
R_{1}=\frac{\left(D-v_{\mathrm{f}} Q_{1}\right)}{\left(D-v_{\mathrm{m}} Q_{1}\right) Q_{2}} \\
P_{2}=\left\{\left(v_{\mathrm{m}} D-Q_{1}\right)\left[\frac{b^{4}\left(1+v_{\mathrm{m}}\right) \ln \left(\frac{b}{a}\right)}{\left(b^{2}-a^{2}\right)^{2}}-\frac{b^{2}+a^{2}+\left(3 b^{2}-a^{2}\right) v_{\mathrm{m}}}{4\left(b^{2}-a^{2}\right)}\right]\right. \\
\left.-\left(v_{\mathrm{f}} D-Q_{1}\right) \frac{\left(1+v_{\mathrm{f}}+2 v_{\mathrm{f}}^{2}\right) E_{\mathrm{m}}}{4 E_{\mathrm{f}}}\right\}\left[\left(D-v_{\mathrm{m}} Q_{1}\right) Q_{2}\right]^{-1} \\
P_{3}=\frac{-a^{2} v_{\mathrm{m}}\left(v_{\mathrm{m}} D-Q_{1}\right)}{\left(b^{2}-a^{2}\right)\left(D-v_{\mathrm{m}} Q_{1}\right) Q_{2}}
\end{gathered}
$$

and where

$$
\begin{gathered}
Q_{1}=2\left(\frac{v_{\mathrm{f}} E_{\mathrm{m}}}{E_{\mathrm{f}}}+\frac{a^{2} v_{\mathrm{m}}}{b^{2}-a^{2}}\right) \\
Q_{2}=1-\frac{v_{\mathrm{m}}\left(v_{\mathrm{m}} D-Q_{1}\right)}{D-v_{\mathrm{m}} Q_{\mathrm{I}}}
\end{gathered}
$$

Whereas Eq. (6) is a generalized solution, Eqs. (3), (4) and (5) contain simplifications. Limitations in the application of Eqs. (3), (4) and (5) are hence expected. To examine these limitations, $\tau_{0}$ obtained from Eqs. (3) to (6) and normalized by $\sigma_{0}$ as a function of $b / a$ is shown in Figs. $2 \mathrm{a}$ and $2 \mathrm{~b}$ for $v_{\mathrm{f}}=0.2, v_{\mathrm{m}}=0.25$ and $E_{\mathrm{f}} / E_{\mathrm{m}}=1$ and 2 , respectively. The following results are concluded. (1) The radial dependence of of should be considered when $b / a$ is close to one (i.e., the matrix becomes a coating) $[16,17]$. (2) The radial dependence of both of and $\sigma_{\mathrm{m}}$ can generally be ignored except that when the matrix becomes a coating. However, including the radial dependence of $\sigma_{\mathrm{m}}$ in the analysis, a slightly better result is obtained. (3) when $E_{\mathrm{f}} / E_{\mathrm{m}}$ increases, the applicable range of b/a decreases for Eq. (4) but increases for Eqs. (3) and (5). 



Fig. 2. Comparison of the $\tau_{\mathrm{o}} / \sigma_{\mathrm{o}} v s$. b/a relation among results obtained from various simplifications for $v_{\mathrm{f}}=0.2, v_{\mathrm{m}}=0.25$, and (a) $E_{\mathrm{f}} / E_{\mathrm{m}}=1$, (b) $E_{\mathrm{f}} / E_{\mathrm{m}}=2$. 


\section{FRICTIONAL INTERFACES}

For a frictional interface, the axial stresses in the fiber and the matrix, $\sigma_{\mathrm{f}}$ and $\sigma_{\mathrm{m}}$, vary slowly over distances comparable to the fiber radius. In this case, the characteristics of stresses in any section transverse to the axial direction can be approximated by a Lamé problem, and both of and $\sigma_{\mathrm{m}}$ can be approximated to be independent of the radial coordinate $[9,19]$. When the debonded interface is subjected to Coulomb friction, the interfacial shear stress is proportional to the radial compression at the interface. With a component of the interfacial radial stress induced by Poisson's effect, consideration of Poisson's effect in the analysis is essential [20]. Also, in the presence of interfacial asperities, an interfacial compressive stress is induced as the fiber attempts to slide past the matrix [21-23]. This would modify the interfacial frictional stress; however, this interfacial asperities effect will not be addressed here. When Poisson's effect is considered, the stress analysis is formidable. A simple treatment of Poisson's effect is hence addressed as follows.

To maintain continuity of the radial displacement at the interface, an interfacial radial stress, $\sigma_{\mathrm{p}}$, is induced due to Poisson's effect which is a linear function of the axial stress in the fiber, of. Due to the stress transfer between the fiber and the matrix, of varies non-linearly along the sliding length. Hence, when Poisson's effect is considered pointwise, $\sigma_{\mathrm{p}}$ varies non-linearly along the sliding length which, in turn, results in complication in the analyses. To simplify the analyses, Poisson's effect is treated in an average sense [24]; i.e., the average values along the sliding length of both $\sigma_{\mathrm{p}}$ and the interfacial frictional stress, $\tau_{1}$, are considered, in the analyses. With an average of $\tau_{1}$ along the sliding length, of varies linearly along the sliding length. Using this averaging technique, both stress analyses and the solutions are greatly simplified. To justify the applicability and to illustrate the simplicity of the averaging technique, comparisons are made among solutions obtained for fiber pullout from various simplifications. Examples of applying the averaging technique to fiber push-in are also shown.

\section{Fiber pullout}

When the radial dependences of both $\sigma_{\mathrm{f}}$ and $\sigma_{\mathrm{m}}$ are ignored and Poisson's effect is considered pointwise in the analysis, the equation governing the axial stress distribution, of, along the fiber length is a first order differential equation. The stress, $\sigma_{t}$, required to pull out a fiber from the matrix as a function of the embedded fiber length, $t$, is [9]

$$
\sigma_{t}=\frac{D E_{\mathrm{f}} \sigma_{\mathrm{C}}}{v_{\mathrm{f}} E_{\mathrm{m}}}\left\{1-\exp \left[\frac{-2 \mu\left(\frac{a^{2} v_{\mathrm{m}}}{b^{2}-a^{2}}+\frac{v_{\mathrm{f}} E_{\mathrm{m}}}{E_{\mathrm{f}}}\right)}{a D}\right]\right\}
$$

where $\mu$ is the coefficient of friction, and $\sigma_{c}$ is residual clamping stress at the interface.

When (1) the radial dependence of $\sigma_{f}$ is ignored, (2) the radial dependence of $\sigma_{\mathrm{m}}$ is considered, and (3) Poisson's effect is considered pointwise in the analysis, the equation governing $\sigma \mathrm{f}$ is a second order differential equation. The $\sigma_{t}-t$ relation is [25] 


$$
\begin{aligned}
\sigma_{\mathrm{t}}= & \left\{\frac{\left(b^{2}-a^{2}\right) E_{f} D\left\{\left(m_{2}-m_{1}\right) \exp \left[\left(m_{1}+m_{2}\right) t\right]+m_{1} \exp \left(m_{1} t\right)-m_{2} \exp \left(m_{2} t\right)\right\}}{\left(b^{2}-a^{2}\right) v_{\mathrm{f}} E_{\mathrm{m}}+a^{2} v_{\mathrm{m}} E_{\mathrm{f}}}\right. \\
& \left.+\frac{2 \mu\left[\exp \left(m_{1} t\right)-\exp \left(m_{2} t\right)\right]}{a}\right\} \sigma_{\mathrm{C}} \\
& \times\left\{\frac{\left(b^{2}-a^{2}\right) v_{\mathrm{f}} E_{\mathrm{m}}\left[m_{1} \exp \left(m_{1} t\right)-m_{2} \exp \left(m_{2} t\right)\right]+a^{2} v_{\mathrm{m}} E_{\mathrm{f}}\left(m_{1}-m_{2}\right) \exp \left[\left(m_{1}+m_{2}\right) t\right]}{\left(b^{2}-a^{2}\right) v_{\mathrm{f}} E_{\mathrm{m}}+a^{2} v_{\mathrm{m}} E_{\mathrm{f}}}\right. \\
& \left.+\frac{2 \mu v_{\mathrm{f}} E_{\mathrm{m}}\left[\exp \left(m_{1} t\right)-\exp \left(m_{2} t\right)\right]}{a E_{f} D}\right\}^{-1}
\end{aligned}
$$

where $m_{1}$ and $m_{2}$ are given by

$$
\begin{aligned}
& m_{1}=\frac{-A_{1}+\left(A_{1}^{2}-4 A_{2}\right)^{1 / 2}}{2} \\
& m_{2}=\frac{-A_{1}-\left(A_{1}^{2}-4 A_{2}\right)^{1 / 2}}{2}
\end{aligned}
$$

and

$$
\begin{gathered}
A_{1}=\frac{a\left(1-\frac{b^{2}}{a^{2}}\right) D}{2 \mu v_{\mathrm{m}}\left(1+v_{\mathrm{m}}\right)\left[b^{2} \ln \left(\frac{b}{a}\right)-\frac{b^{2}-a^{2}}{2}\right]} \\
A_{2}=\frac{\left(1-\frac{b^{2}}{a^{2}}\right)\left(\frac{E_{\mathrm{m}} v_{\mathrm{f}}}{E_{\mathrm{f}} v_{\mathrm{m}}}\right)-1}{\left(1+v_{\mathrm{m}}\right)\left[b^{2} \ln \left(\frac{b}{a}\right)-\frac{b^{2}-a^{2}}{2}\right]}
\end{gathered}
$$

When the radial dependences of both $\sigma_{\mathrm{f}}$ and $\sigma_{\mathrm{m}}$ are ignored and Poisson's effect is considered in an average sense, the equation governing of is a simple nonlinear equation. The $\sigma_{t} t$ relation is [19]

$$
\sigma_{\mathrm{t}}=\frac{-2 t \mu \sigma_{\mathrm{C}}}{a+\frac{t \mu}{D}\left(\frac{v_{\mathrm{f}} E_{\mathrm{m}}}{E_{\mathrm{f}}}-\frac{a^{2} v_{\mathrm{m}}}{b^{2}-a^{2}}\right)}
$$


It is noted that when the applied axial tension on the fiber increases and reaches a critical value, the induced interfacial radial tension due to Poisson's effect can counter the residual clamping stress and result in a frictionless interface $[5,9,12,24,25]$. This would occur starting at the loaded end, where Poisson's effect is the greatest, and is not considered in using the averaging technique. Hence, the analysis using the averaging technique for fiber pull-out is subjected to the condition that the pull-out stress is limited by a critical value such that $[9,12,24,25]$

$$
\sigma_{t} \leq \frac{-D E_{f} \sigma_{C}}{v_{f} E_{m}}
$$

Fiber pull-out tests have been performed on a single stainless steel fiber embedded in an epoxy resin matrix [5] where $E_{\mathrm{f}}=170 \mathrm{GPa}, E_{\mathrm{m}}=3.65 \mathrm{GPa}, v_{\mathrm{f}}=0.35, v_{\mathrm{m}}=0.39, \sigma_{\mathrm{c}}=-12.25 \mathrm{MPa}, a=$ $75 \mathrm{~mm}$ and $b=7.5 \mathrm{~mm}$. The coefficient of friction, $\mu$, at the interface was modified by a coating of the release agent on the steel fiber, such that $\mu$ is 0.53 and 0.1 for the clean and the coated fibers, respectively [5]. Inserting the above material properties into Eqs. (9), (10) and (13), excellent agreement among above equations and experimental results is obtained (Fig. 3). The fiber pullout stress, $\sigma_{t}$, obtained from Eq. (9) is higher than that obtained from Eq. (10) by less than $1 \%$ for the entire range of the embedded fiber length shown in Fig. 3; the two predictions can hardly been distinguished (Fig. 3).

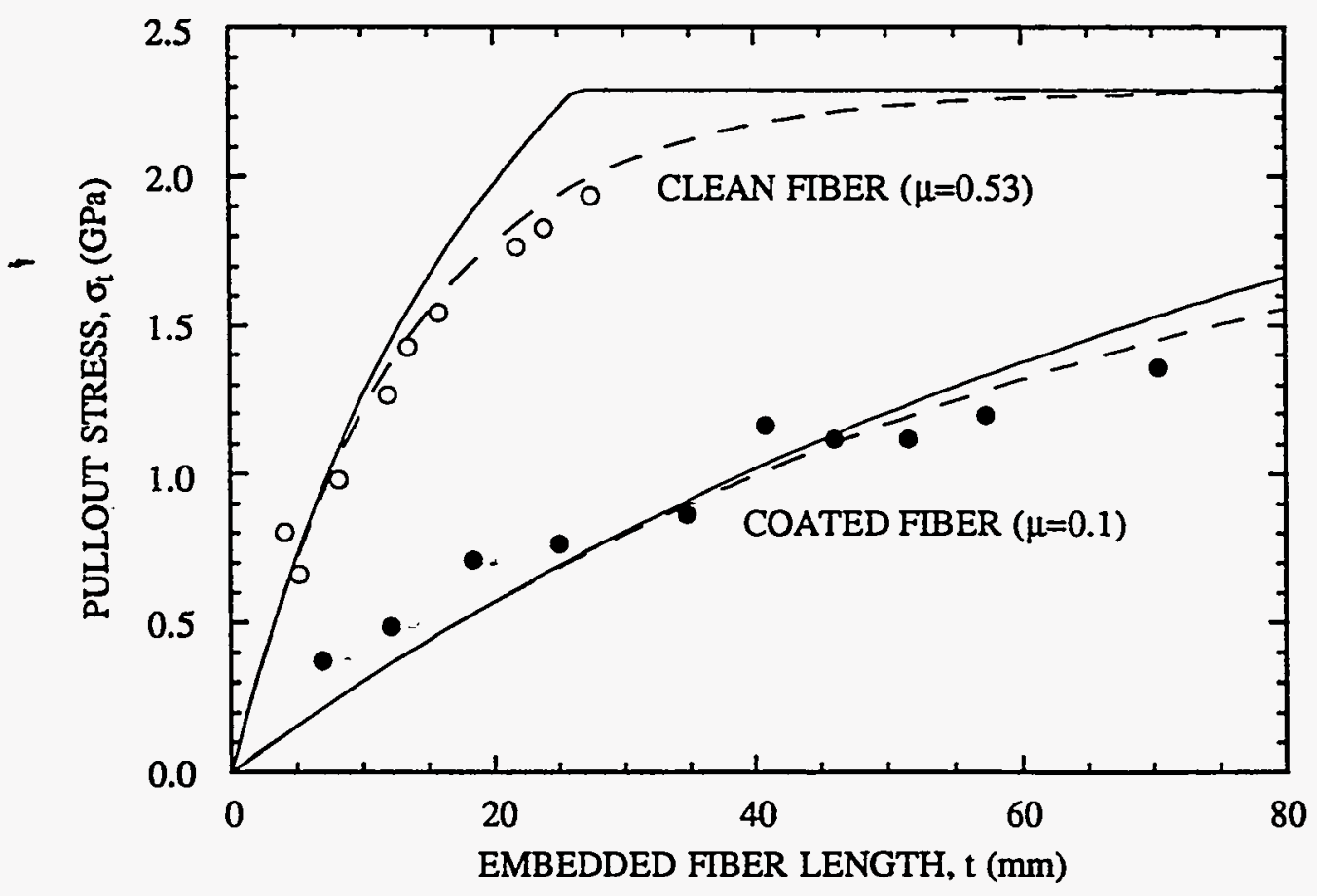

Fig. 3. The fiber pullout stress $v s$. embedded fiber length (i.e., $\left.\sigma_{t}-t\right)$ relation. $(-\longrightarrow)$ : Eqs. (9) and (10), (—): Eq. (13), and (o and •): experimental data [5]. 
Fiber push-in tests have been performed on Nicalon fiber-reinforced macro-defect-free (MDF) cement composites [26]. The material properties are: $E_{\mathrm{f}}=200 \mathrm{GPa}, E_{\mathrm{m}}=80 \mathrm{GPa}, v_{\mathrm{f}}=0.15$,

$v_{\mathrm{m}}=0.2, a=5$ to $12 \mu \mathrm{m}$. The composite contains one row of fibers (i.e., the fiber volume fraction approaches zero). The fibers are coated with stearic acid or silane prior to their incorporation in a MDF cement matrix to modify the interfacial properties. The experimental load-displacement relations during the loading-unloading process of the push-in test are shown in Figs. $4 \mathrm{a}$ and $4 \mathrm{~b}$ for composites with these two different coatings. The averaging Poisson's effect technique has been applied successfully to analyze the results obtained from fiber push-in tests [27]. Four unknown parameters in the analysis are determined: the loading stress required to debond the interface, $\sigma_{\mathrm{d}}$, the residual clamping stress at the interface, $\sigma_{\mathrm{C}}$, the residual axial stress in the fiber, $\sigma_{\mathrm{Z}}$, and the coefficient of friction, $\mu$.

By fitting the theoretical predictions [27] to the experimental results [26], the interfacial properties evaluated are: $\sigma_{\mathrm{d}}=-130 \mathrm{MPa}, \sigma_{\mathrm{C}}=-17 \mathrm{MPa}, \sigma_{\mathrm{Z}}=-61.35 \mathrm{MPa}$ and $\mu=0.18$ for the stearic acid coated specimen ( $a=9 \mu \mathrm{m}$ and $b / a=100$, Fig. $4 \mathrm{a}$ ), and $\sigma_{\mathrm{d}}=-276 \mathrm{MPa}, \sigma_{\mathrm{C}}=-32.5 \mathrm{MPa}, \sigma_{\mathrm{Z}}=-$ $117.3 \mathrm{MPa}$ and $\mu=0.3$ for the silane coated specimen ( $a=8.5 \mu \mathrm{m}$ and $b / a=100$, Fig. $4 \mathrm{~b}$ ). Compared to the silane coated specimen, the stearic acid coated specimen exhibits significantly reduced interfacial bonding, residual stresses, and frictional resistance. For the silane coated specimen, the fiber protrudes above the matrix after complete unloading. The deviation between the predicted and the experimental unloading curves occurring near the peak load for the silane coated specimen (Fig. 4b) is due to the measurement error in the experimental data [26]. This error results from hysteresis effects in the indentation load train, which arises during load reversal. Normally, the hysteresis error is a relatively small component of the fiber sliding displacement. However, for the silane coated specimen, fiber sliding is quite limited such that the hysteresis during load reversal has a measurable effect on the unloading curve.

\section{CONCLUDING REMARKS}

Simplifications adopted in the shear lag model, which has been used extensively to analyze the stress transfer in fiber-reinforced composites, are reviewed in the present study. These simplifications are usually achieved by ignoring the radial dependences of axial stresses and/or ignoring Poisson's effect in the analysis. However, depending upon the boundary conditions (i.e., bonded or frictional) at the interface, simplifications pertinent to these two cases should be different.

For bonded interfaces, the stress transfer is fast near the loaded region, and significant stress gradients are expected not only in the axial direction but also in the radial direction. It is found that the radial dependences of axial stresses can generally be ignored. However, when the radii of the fiber and the matrix are similar, the radial dependence of the axial stress in the fiber should be considered (see Fig. 2). The stress transfer occurs through the interfacial shear stress. The interfacial radial stress induced by Poisson's effect has a negligible effect on the interfacial shear stress. Hence, Poisson's effect can be ignored.

For frictional interfaces, the axial stresses in the fiber and the matrix vary slowly over distances comparable to the fiber radius, and the characteristics of stresses in any section transverse to the axial direction can be approximated by a Lamé problem. Hence, the radial dependences of axial stresses can be ignored. The interfacial frictional stress is proportional to the radial compression at the interface (i.e., Coulomb friction). Hence, the component of the interfacial radial stress induced by Poisson's effect cannot be ignored. In the presence of Poisson's effect, the stress analysis becomes much more complex. However, Poisson's effect along the sliding length can be treated in an average sense, and both the stress analysis and the analytical solutions for fiber pull-out are greatly simplified. 

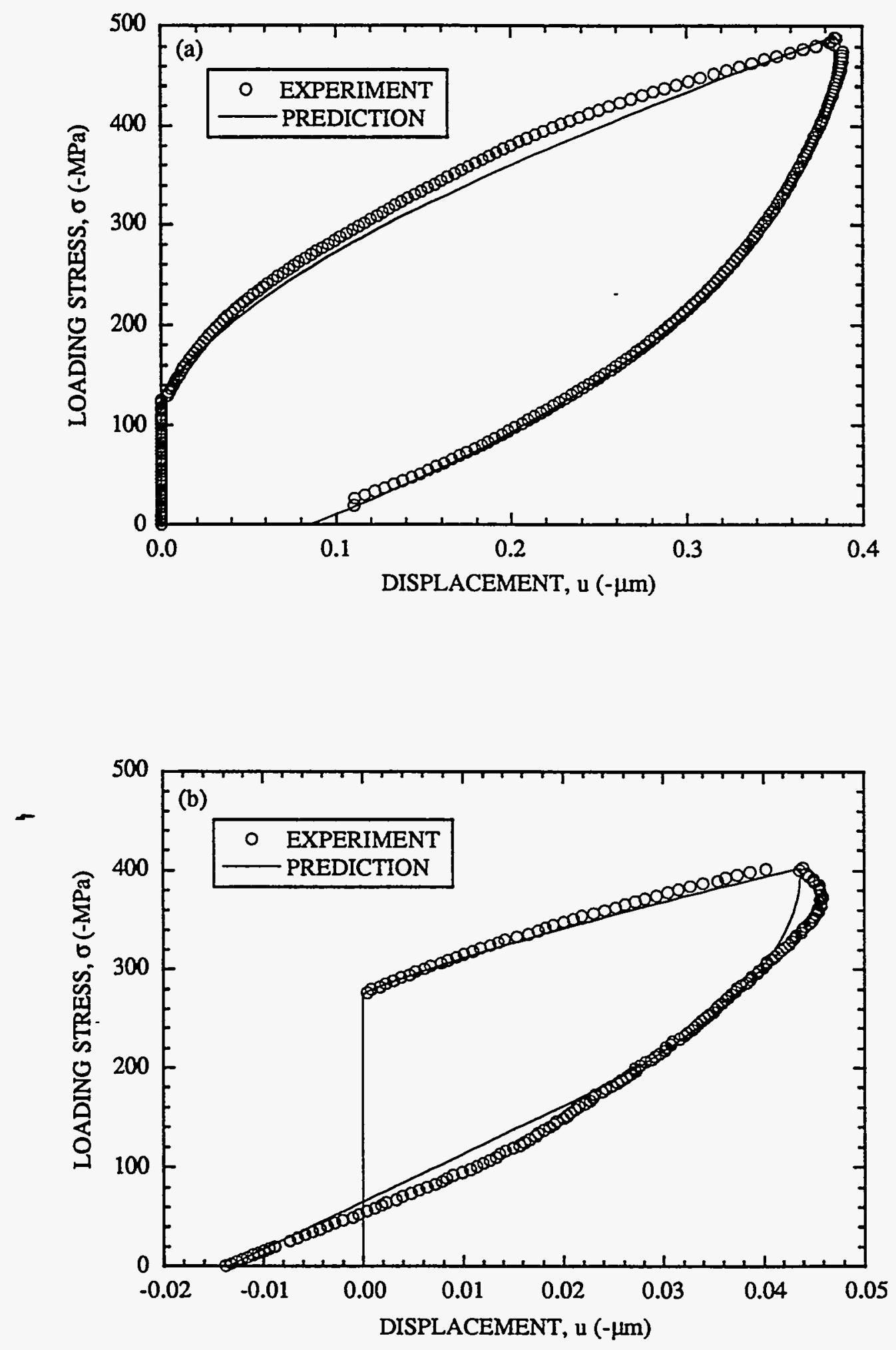

Fig. 4. The loading stress-displacement relation of fiber push-in tests for Nicalon fiber(a) stearic acid-coated, and (b) silane-coated reinforced MDF cement composites. 


\section{ACKNOWLEDGMENTS}

The author thanks Dr. P. F. Becher and Dr. H. T. Lin for reviewing the manuscript. Research jointly sponsored by the U.S. Department of Energy, Division of Materials Sciences, Office of Basic Energy Sciences, and Assistant Secretary for Energy, Efficiency and Renewable Energy, Office of Industrial Technologies, Energy Efficiency Division and Continuous Fiber Ceramic Composites Program, under contract DE-AC05-84OR21400 with Martin Marietta Energy Systems, Inc.

\section{REFERENCES}

1. A. G. Evans and R. M. McMeeking, Acta Metall., 34 (12), 2435-2441 (1986).

2. P. F. Becher, C. H. Hsueh, P. Angelini and T. N. Tiegs, J. Am. Ceram. Soc., 71 (12), 1050-1061 (1988).

3. H. L. Cox, Brit. J. Appl. Phy., 3, 72 (1952).

4. P. Lawrence, J. Mater. Sci., 7 (1) 1-6 (1972).

5. A. Takaku and R. G. C. Arridge, J. Phys. D: Appl. Phys., 6, 2038 (1973).

6. M. R. Piggott, Load Bearing Fiber Composites, (Pergamon Press, Elmsford, NY, 1980), p. 62.

7. B. Budiansky, J. W. Hutchinson and A. G. Evans, J. Mech. Phys. Solids, 34 (2), 167-89 (1986).

8. C. H. Hsueh, J. Mater. Sci. Lett., 7 (5), 497-500 (1988).

9. Y. C. Gao, Y. W. Mai and B. Cotterell, J. Appl. Math. and Phys. (ZAMP), 39 (7), $550-72$ (1988).

10. D. K. Shetty, J. Am. Ceram. Soc., 71 (2), C107-109 (1988).

11. R. J. Kerans and T. A. Parthasarathy, J. Am. Ceram. Soc., 74 (7), 1585-1596 (1991).

12. J. K. Kim, C. Baillie, and Y. W. Mai, J. Mater. Sci., 27, 3143 (1992).

13. C. H. Hsueh, J. Mater. Sci. Lett., 10 (1), 29-32 (1991).

14. D. H. Grande, J. F. Mandell and K. C. C. Hong, J. Mater. Sci., 23 (1), 311-328 (1988).

15. L. N. McCartney, Proc. Roy. Soc. Lond., A425, 215 (1989).

16. C. H. Hsueh, J. Am. Ceram. Soc., 71 (6), 490-493 (1988).

17. G. H. Hsueh, Mater. Sci. and Eng., A154 (7), 125-132 (1992).

18. C. H. Hsueh, Mater. Sci and Eng., A123 (1), 1-11 (1990).

19. J. W. Hutchinson and H. M. Jenson, Mech. Mater., 9, 139 (1990).

20. C. H. Hsueh, J. Mater. Sci. Lett., 8 (6), 739-42 (1989).

21. J. Bowling and G. W. Groves, J. Mater. Sci., 14, 431 (1979).

22. P. D. Jero, R. J. Kerans, and T. A. Parthasarathy, J. Am. Ceram. Soc., 74 (11), 2793-801 (1991).

23. T. J. Mackin, P. D. Warren and A. G. Evans, Acta Metall. Mater., 40 (6), 1251-1257 (1992).

24. C. H. Hsueh, Mater. Sci. and Eng., A161 (3), L1-L6 (1993).

25. C. H. Hsueh, Mater. Sci and Eng., A125 (5), 67-73 (1990).

26. M. K. Ferber, A. A. Wereszczak, D. H. Hansen and J. Homeny, Comp. Sci. Tech., 49, 23 (1993).

27. C. H. Hsueh. J. Am. Ceram. Soc.. 76 (12). 3041-50 (1993).

\section{DISCLAIMER}

This report was prepared as an account of work sponsored by an agency of the United States Government. Neither the United States Government nor any agency thereof, nor any of their employees, makes any warranty, express or implied, or assumes any legal liability or responsibility for the accuracy, completeness, or usefulness of any information, apparatus, product, or process disclosed, or represents that its use would not infringe privately owned rights. Reference herein to any specific commercial product, process, or service by trade name, trademark, manufacturer, or otherwise does not necessarily constitute or imply its endorsement, recommendation, or favoring by the United States Government or any agency thereof. The views and opinions of authors expressed herein do not necessarily state or reflect those of the United States Government or any agency thereof. 